\title{
FIXED DRUG ERUPTIONS - A CASE SERIES
}

\section{Anupama Devi Wahengbam', Vijayakumar $\mathbf{S}^{2}$, Sowmya Dogiparthi3', Saranya $\mathbf{M}^{3}$, Jeyakumari Jeevan4,}

${ }^{7}$ Final year Post-graduate, ${ }^{2}$ Senior Resident, ${ }^{3}$ Assistant Professor, ${ }^{4}$ Professor \& Head, Department of Dermatology, Venereology \& Leprosy,

\section{INTRODUCTION}

Fixed drug eruption is a type of cutaneous adverse drug reactions accounting for $4-39 \%$ of all drug eruptions worldwide. ${ }^{[1]}$ Paucity of data in Indian population but a systemic review reported its incidence as $20.13 \%$ amongst Cutaneous Adverse Drug Reactions. ${ }^{[2,3]}$ Here we present a collection of cases observed in our patients.

\section{CASE REPORTS}

CASE NO 1: A $47 \mathrm{yr}$ old with diabetic foot received Inj Metronidazole \& Ceftriazone. Presented with a sharply demarcated hyperpigmented $3.5 \times 2.5 \mathrm{~cm}$ patch over the forehead above the right eyebrow and a circular hyperpigmented patch $1.5 \times 1 \mathrm{~cm}$ with resolving erosion on the genitalia
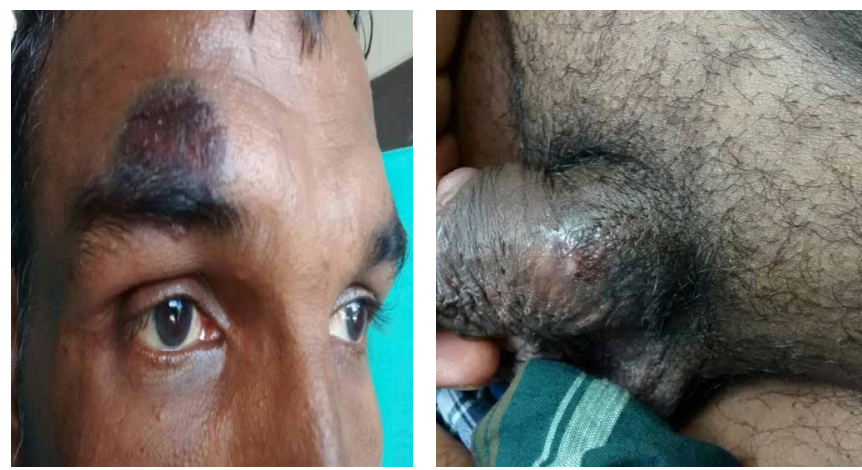

CASE NO 2: A 30 yr old male with multiple oval hyper pigmented patches over arm \& back. The patches were erythematous $\&$ itchy which resolved \& left behind hyperpigmentation on both occasions of taking over the counter medications for pain NSAIDS (Non Steroidal Anti Inflammatory Drugs)

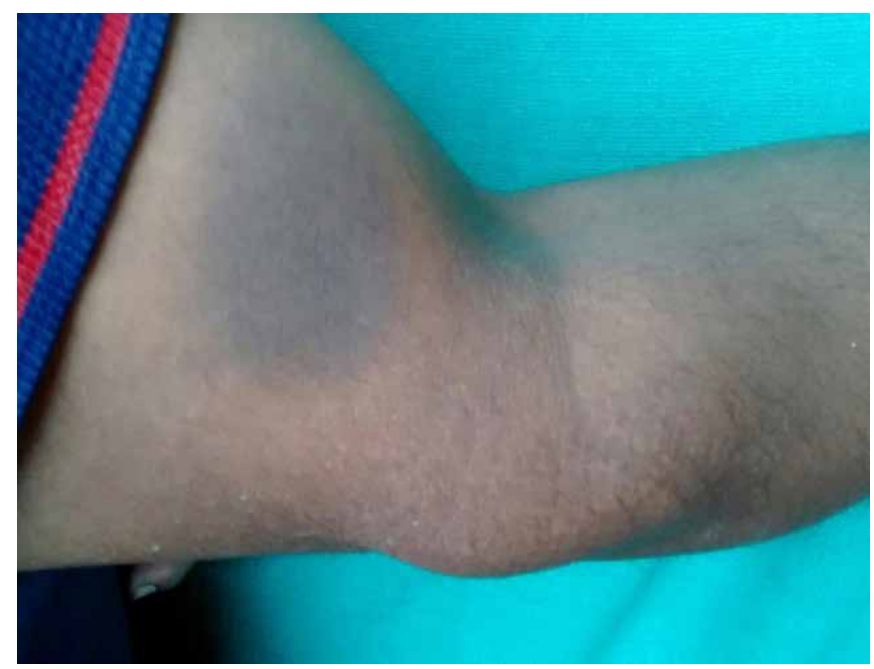

CASE NO 3: A5 yr old child presented with hyper pigmented patches over upper lids \& perioral region with erosions \& crusting on taking Cotrimoxazole prescribed from a Primary health center for fever.
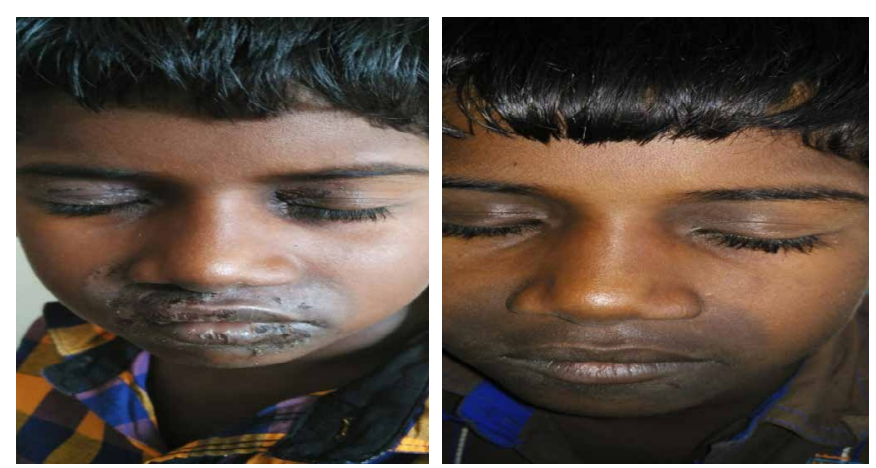

CASE NO 4: A5 yr old male child with recurrent multiple oval to round hyper pigmented patches over trunk every time he gets treatment for cough \&cold from primary health centre with Cotrimoxazole. 

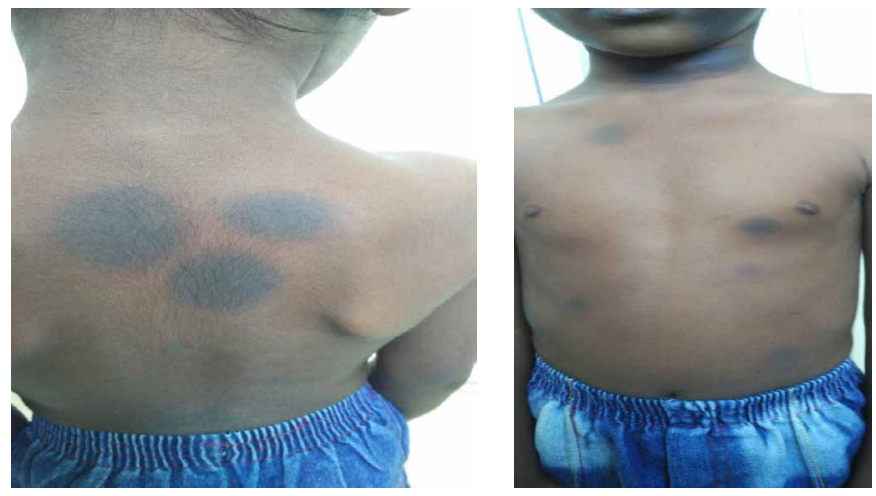

CASE NO 5: A25 year old patient developed lesions over upper lip 2 days after taking over the counter tab Diclofenac (non-steroidal anti-inflammatory drugs) for back pain. He presented with well defined violaceous patch with central eczematous zone seen over upper lip.
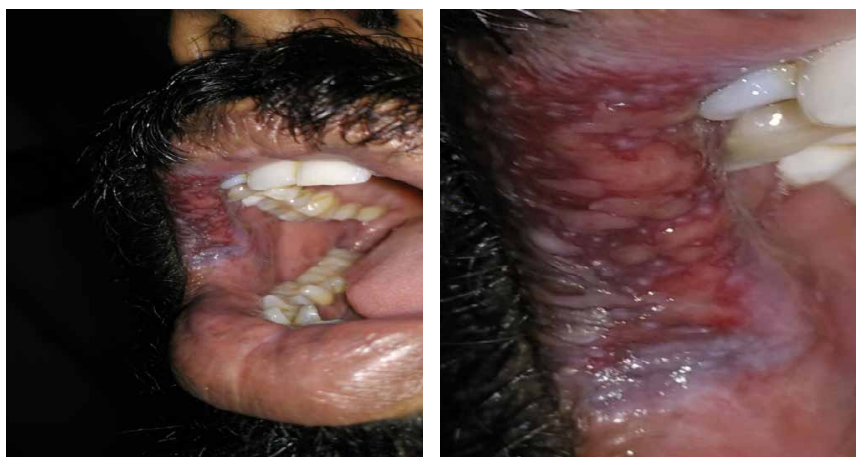

CASE NO 6: A 45 year old male came with c/o sudden onset lesion over the glans. He was prescribed Tab Cefpodoxime by a private practitioner for indication not known.

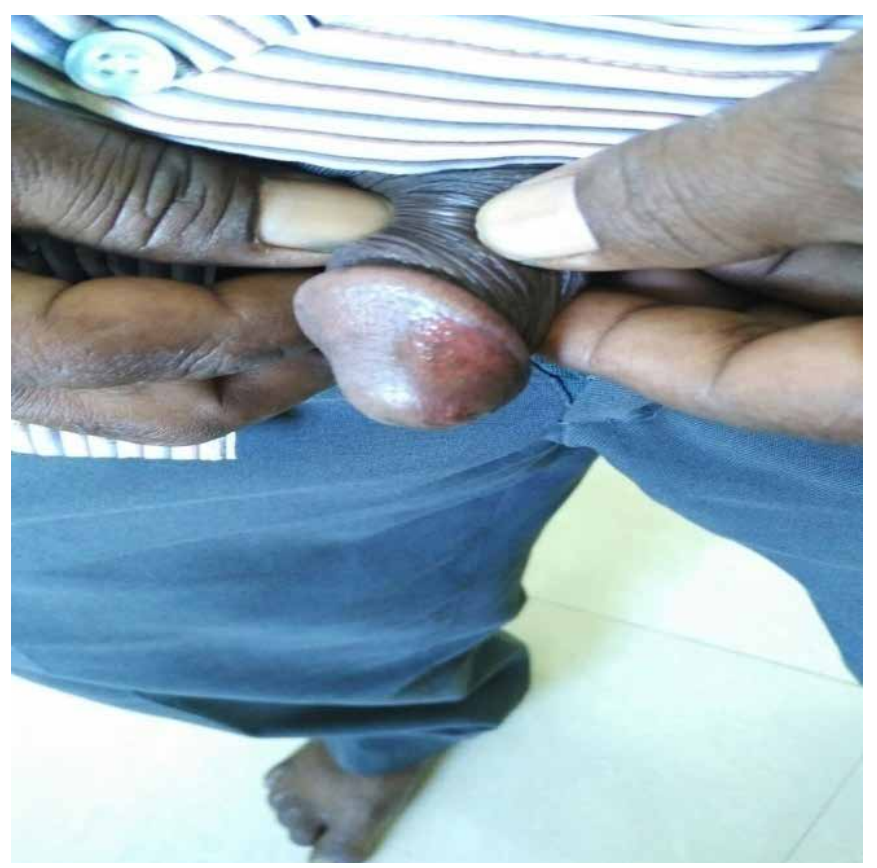

CASE NO 7: A58 year old female presented with oval multiple hyper pigmented patches overthe trunk \& thighs of 1 week duration. She was prescribed oral Norfloxacin and Tinidazole for gastroenteritis elsewhere.

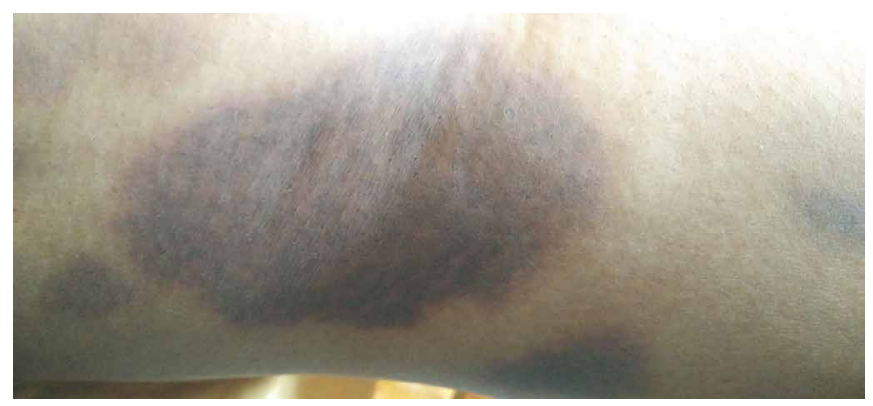

CASE NO 8: A 30 year old male came with sudden onset of fluid filled lesions over the genitalia 2 days after taking tab doxycycline.

$\mathrm{O} / \mathrm{E}$ : Two in number ruptured bulla with erosion over glans penis and shaft.Also over the lower lip.
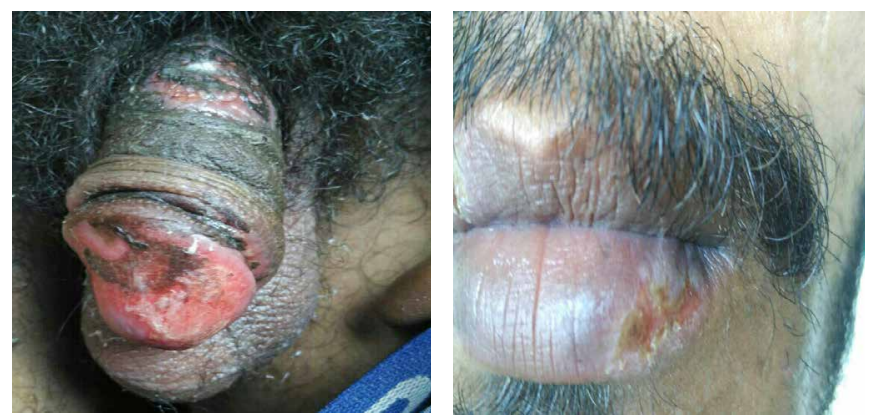

CASE NO 9 \& 10: A 30 yr old with hyperpigmented dusky patch with healing erosion in the centre over the lips and a $42 \mathrm{yr}$ old female presented with hyperpigmented patches with erosions.

Both have taken OTC medication NSAIDS (Non steroidal anti-inflammatory drugs)
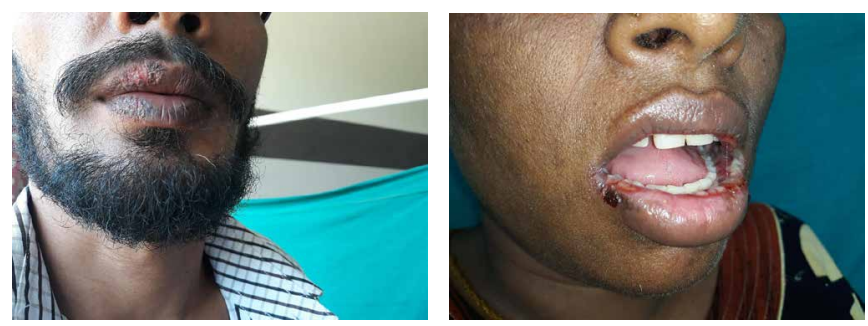

Using WORLD HEALTH ORGANISATION UPPSALA MONITORING CENTER system causality assessment, a diagnosis of fixed drug eruption were made in all the above cases. 


\begin{tabular}{|c|c|}
\hline CERTAIN & $\begin{array}{l}\text { Event/lab test abnormality with } \\
\text { plausible time relationship to drug } \\
\text { intake. } \\
\text { Cannot be explained by disease or } \\
\text { other drugs. } \\
\text { Response to withdrawal Plausible } \\
\text { (Pharmacologically,pathologically) } \\
\text { Event definitive pharmacologically } \\
\text { or phenomenologically } \\
\text { Re-challengesatis factory, if } \\
\text { necessary. }\end{array}$ \\
\hline $\begin{array}{l}\text { PROBABLE/ } \\
\text { LIKELY }\end{array}$ & $\begin{array}{l}\text { Event/lab test abnormality, with } \\
\text { reasonable time relationship to drug } \\
\text { intake. } \\
\text { Unlikely to be attributed to disease } \\
\text { or other drugs } \\
\text { Response to withdrawal clinically } \\
\text { reasonable } \\
\text { Re-challenge not required }\end{array}$ \\
\hline
\end{tabular}

\section{DISCUSSION}

Fixed drug eruption is a cutaneous adverse drug reaction characterized by recurrent well defined lesions occurring in same sites each time the offending drug is taken. ${ }^{[1]}$ Fixed Drug Eruption has been reported in all ages. The patients ranged from 5 to 58 years old in our cases.

Pathophysiology: Fixed Drug Eruption is a form of classical delayed type hypersensitivity reaction \& skin resident $\mathrm{T}$ cells are key mediators. ${ }^{[1]}$

\section{CLINICAL FEATURES}

Initial episode develops 1-2 weeks after 1st exposure to drug. Subsequently, develops $30 \mathrm{~min}-8$ hour after re-exposure to drug. ${ }^{[1,2]}$

Typically, Fixed Drug Eruption presents as sharply defined, round or oval erythematous patch or plaque which evolves to become dusky, violaceous \& occasionally eczematous, vesicular or bullous. ${ }^{[1]}$

May be solitary or few lesions. Multiple lesions may develop as consequence to repeated challenges. ${ }^{[1]}$

Common sites-Muco cutaneous junctions lips \& genitals, limbs more than trunk.

Drug induced clinical pattern - NSAIDs (non steroidal antiinflammatory drugs), Tetracycline, Cotrimaxazole over genitals \& lips were seen in our cases.

Common drugs implicated Sulfonamides, NSAIDs, Tetracyclines, Quinolones, Metronidazole observed.

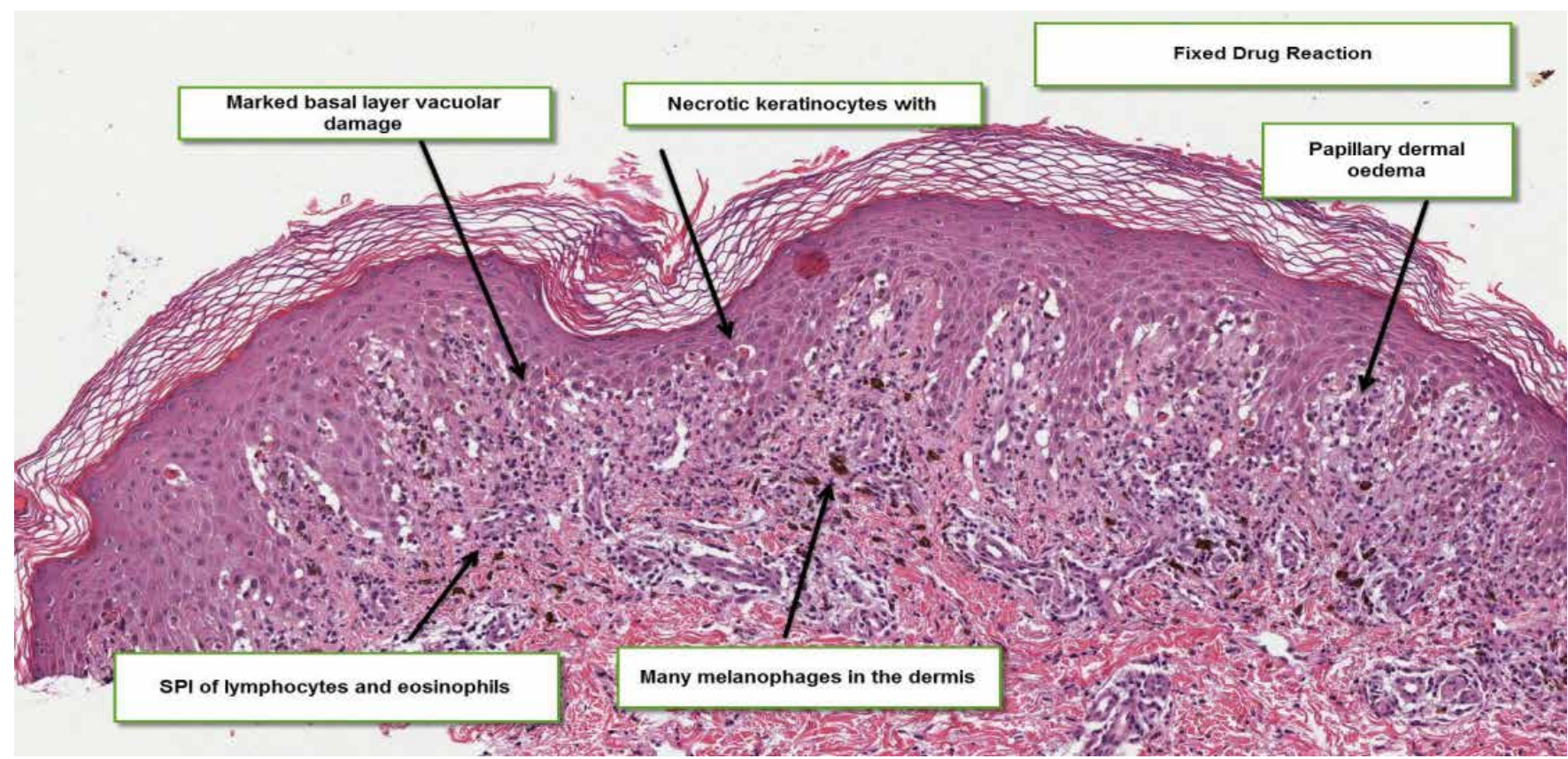




\section{TYPES OF FDE (FIXED DRUG ERUPTIONS) 2}

- Pigmenting FDE

- Non pigmented FDE

- Generalised FDE

Cellulitis eruption FDE

- Wandering FDE

- Bullous FDE

- Eczematous FDE

- Urticaria FDE

- Erythema dyschromicum perstans type FDE

- Psoriasiform FDE

- Oral FDE

- Vulvitis FDE

COMPLICATIONS: Post inflammatory hyper pigmentation which persists for several months after acute episode was the commonest noted in our cases.

\section{INVESTIGATIONS}

1. Oral provocation of implicated drug is gold standard to confirm causation but avoided in the Bullous Fixed Drug Eruption. ${ }^{[1,4-8]}$

2. Patch test- not done however it can be positive only in $50 \%$ of cases. ${ }^{[1]}$

3. Causality assessments-WHO-Uppsala monitoring centre system..$^{[5,6,9]}$

MANAGEMENT: Implicated offending drug was advised to be avoided.
- Use of topical corticosteroid.

- Systemic corticosteroids-for multiple lesions.

\section{CONCLUSION}

Fixed drug eruption is one of the commonest Cutaneous Adverse Drug Reactions \& knowledge about common drugs causing it is essential for its management.

\section{REFERENCES}

4. Griffiths C, Barkar J, Bleiker T, Chalmers R, Creamer D. Rook's Textbook of Dermatology, 9th edition. Willey Blackwell; 2016 p: 118.

5. Sacchidanand, Oberai C, Inamadar AC. IADVL Textbook of Dermatology,4th edition. Bhalani: 2013. p: 2365-7.

6. Patel TK, Thakkar SH, Sharma DC. Cutaneous adverse reactions in Indian population: A systemic review. Indian Dermatol Online J 2014:5(Suppl2):S76-86.

7. Pai WV, Narayanshetty N, Likkeri SB, Shukla P, Bhandari P, Rai V. Retrospective analysis of fixed drug eruptions among patients attending a tertiary care center in southern India. Indian J Dermatol 2014;80(2):194.

8. Kameswari PD, Selvaraj N, Adhimoolam M. Fixed drug eruptions caused by cross reactive quinolones.J Basic Clin Pharm 2014;5(2):54-5.

9. Gupta LK, Beniwal R, Khare AK, Mittal A, Mehta S, Balai M. Non-pigmenting fixed drug eruption due to fluoroquinolones. Indian J Dermatol 2017;83(1):108-12.

10. Filiz C, Sirin Y, Sema A, Pembegul G. Acetaminophen-induced fixed drug eruption. Indian J Pharmacol. 2016;48(2):219-20.

11. Agarwala MK, Mukhopadhyay S, Rajasekhar M, Peter CVD. Bullous fixed drug eruption probably induced by paracetamol. Indian J Dermatol 2016;61:121

12. The use of the WHO-UMC system for standardised case causality assessment. Available from:http://www.who.int/medicines/areas/quality_safety/safety_ efficacy/WHOcausalit [Last accessed on 2019 May 25]. 